\title{
Determinants of prevalence and intensity of infection with malaria parasites in the Blue Tit
}

\author{
Edyta Podmokła $\cdot$ Anna Dubiec $\cdot$ Szymon M. Drobniak • \\ Aneta Arct · Lars Gustafsson · Mariusz Cichoń
}

Received: 28 January 2014/ Accepted: 26 February 2014/Published online: 16 March 2014

(C) The Author(s) 2014. This article is published with open access at Springerlink.com

\begin{abstract}
Parasite species are usually specialists utilising specific host species, but parasite assemblages may differ substantially even between populations of the same species and show seasonal and annual fluctuations. Host characteristics such as individual age and sex may also affect parasite species composition and abundance. Here, we report the occurrence of malaria parasites in the Blue Tit (Cyanistes caeruleus) inhabiting Gotland (Sweden) across 5 years. Using PCR-based techniques, we found eight cytochrome $b$ lineages belonging to genus Plasmodium (pTURUD1, pBT7, pSGS1, pSW2, pGRW11) and Haemoproteus (hPARUS1, hPHSIB1, hWW2) with the overall prevalence of $65 \%$. The Plasmodium infections predominated (prevalence of $49.5 \%$ ), whereas Haemoproteus infection rate was much lower (prevalence of $16.5 \%$ ). We showed significant differences in infection status between study years and age classes when all parasite lineages were analysed together or the two most common lineages were analysed separately. Overall, older birds showed higher prevalence. A significant interaction between year and genus effect significantly explained variation in infection intensity. This interaction stems from a significant yearly variation of the infection intensity with Plasmodium, while
\end{abstract}

E. Podmokła $(\bowtie)$ · S. M. Drobniak · A. Arct · M. Cichoń Institute of Environmental Sciences, Jagiellonian University, Kraków, Poland

e-mail: edyta.podmokla@uj.edu.pl

\author{
A. Dubiec \\ Museum and Institute of Zoology, Polish Academy of Sciences, \\ Warsaw, Poland \\ L. Gustafsson \\ Department of Animal Ecology, Evolutionary Biology Centre, \\ Uppsala University, Uppsala, Sweden
}

such an effect is not present for Haemoproteus infections. More importantly, the intensity of infection with Haemoproteus was significantly higher than with Plasmodium in 3 out of the 4 study years with data.

Keywords Avian malaria $\cdot$ Haemoproteus . Plasmodium $\cdot$ Host-parasite interactions

\section{Zusammenfassung}

Einflussfaktoren für Prävalenz und Schwere von Infektionen mit Malariaerregern bei Blaumeisen

Parasitäre Arten sind normalerweise Spezialisten, die sich bestimmter Wirtsarten bedienen; die Parasitenzusammensetzung kann sich aber selbst zwischen verschiedenen Populationen derselben Wirtsart stark unterscheiden und saisonale sowie jährliche Schwankungen zeigen. Auch individuelle Wirtseigenschaften wie Alter und Geschlecht können die Artzusammensetzung und die Häufigkeit der Parasiten beeinflussen. Hier stellen wir die Verbreitung von Malariaerregern bei Blaumeisen (Cyanistes caeruleus) in Gotland (Schweden) über einen Zeitraum von fünf Jahren vor. Mithilfe PCR-basierter Methoden identifizierten wir acht Cytochrom b-Linien aus den Gattungen Plasmodium (pTURUD1, pBT7, pSGS1, pSW2, pGRW11) und Haemoproteus (hPARUS1, hPHSIB1, hWW2) mit einer Gesamtprävalenz von $65 \%$. Plasmodiuminfektionen überwogen mit einer Prävalenz von $49.5 \%$, wohingegen die Infektionsrate durch Haemoproteus mit einer Prävalenz von $16.5 \%$ deutlich geringer war. Es ließen sich signifikante Unterschiede im Infektionsstatus zwischen den einzelnen Untersuchungsjahren sowie zwischen den Altersklassen nachweisen, sowohl wenn alle Parasitenstämme gemeinsam analysiert wurden als auch wenn die 
beiden häufigsten Stämme getrennt ausgewertet wurden. Insgesamt waren ältere Vögel häufiger befallen. Eine deutliche Wechselwirkung zwischen dem Jahr und dem Gattungseffekt lieferte eine signifikante Erklärung für die Variation in der Infektionsschwere. Diese Wechselbeziehung beruht auf einer signifikanten jährlichen Variation der Infektionsschwere mit Plasmodien, wohingegen ein solcher Effekt bei Haemoproteus-Infektionen nicht beobachtet werden konnte. Noch bedeutsamer ist es, dass in drei von vier Untersuchungsjahren mit Daten die Intensität der Infektion mit Haemoproteus deutlich höher lag als die für Plasmodium.

\section{Introduction}

Avian malaria is a widespread vector-borne disease caused by parasites from genus Plasmodium and Haemoproteus (Valkiūnas 2005; Pérez-Tris et al. 2005). These parasites are commonly used as a model system for testing hypotheses in evolutionary ecology (Ricklefs et al. 2004; Knowles et al. 2009). The impact of malaria parasites on the host is highly variable and depends on a specific hostparasite system (e.g. Palinauskas et al. 2008; Lachish et al. 2011a). It has been shown that a host may be differently affected by different parasite species or even genetic lineages of the same species (Asghar et al. 2011; Lachish et al. 2011a), and a parasite can differently affect different host species (Palinauskas et al. 2008, 2011). Thus, to study the effects of avian malaria parasites on the host, it is critical to identify the composition of the parasite assemblage in the host population.

Importantly, the composition of the parasite assemblage as well as the prevalence may significantly vary with time, both seasonally and among years (Bensch et al. 2007; Wood et al. 2007). A number of parameters, associated with the characteristics of the host and the characteristics of its habitat, may contribute to parasite dynamics (e.g. Lachish et al. 2011b). The susceptibility to parasitic infection is known to be associated with host age and sex. Prevalence and intensity of infection may initially increase with age as new infections accumulate during life, but parasitaemia may disappear among oldest individuals due to selective parasite-dependent mortality and developing resistance (Wilson et al. 2001). Sex differences in the prevalence and parasitaemia are frequently reported (e.g. Wood et al. 2007). Higher prevalence of infection is usually observed in males than females among mammals and birds (Poulin 1996; Schalk and Forbes 1997). This has usually been explained by sex-related differences in the probability of encountering the parasite and differences in resistance (Schuurs and Verheul 1990).
Here, based on a large dataset collected over five breeding seasons, we characterise the composition of avian malaria parasites' assemblage as well as the prevalence and parasitaemia in a population of the Blue Tit inhabiting the island of Gotland (SW Sweden). We study variation in the prevalence and the intensity of infection with respect to year, host age and sex. In our analyses, we considered all parasite lineages pooled together to study the general patterns of variation as well as the two most common lineages separately to identify any parasite specific patterns.

\section{Materials and methods}

The study was conducted in years $2008-2012$ on the nestbox breeding population of Blue Tits (Cyanistes caeruleus) inhabiting Gotland, the Swedish Baltic island $\left(57^{\circ} 03^{\prime} \mathrm{N}\right.$, $18^{\circ} 17^{\prime} \mathrm{E}$ ). The study area consists of over a dozen woodlands separated by arable fields. For a detailed description of the study site, see Przybylo et al. (2000). Nestboxes were regularly inspected starting from mid-April to record laying date, clutch size and hatching date. Each year, a subset of breeding pairs experienced brood size manipulation experiment. Some nests were enlarged by 3 extra nestlings while other nests were left unmanipulated. Enlarged broods accounted for c. $21 \%$ of all broods. Some other nests provided extra nestlings for brood size manipulation but these nests were not considered in the present analyses. Adult birds were captured, either in the nest box with traps mounted inside the box or by mist-netting in the close vicinity of the nestbox, while feeding the nestlings. Birds were captured when nestling were 10 days old or older. Birds were aged as yearlings or as at least 2 years old based on the colour of the wing coverts (Svensson 1994) or according to the ringing records. They were sexed based on the presence/absence of the brood-patch, as only females incubate the clutch and the brood patch is visible long after the chicks hatch. Blood samples were collected from all birds to a capillary after a puncture of the wing vein and stored in room temperature in $96 \%$ ethanol.

DNA was extracted using Chelex (Bio-Rad, Munich, Germany) following the manufacturer's protocol (Walsh et al. 1991). Samples were screened for the presence of blood parasites (genus Haemoproteus and Plasmodium) by amplifying a 478-bp fragment of the mitochondrial cyt $b$ gene, using nested polymerase chain reaction (Waldenström et al. 2004). PCR reactions were run as described in Cosgrove et al. (2008), and PCR products processed as described in Podmokla et al. (2014). In cases of double infections, parasite lineages were assigned visually by comparing DNA sequences with the pool of lineages known to occur in this study site. To confirm the reliability of this method, we performed cloning of PCR products of 
Table 1 Primers sequences used for q-PCR. Parasite primers amplified a part of cytochrome $b$, whereas host primers amplified an ultraconserved region of the host nuclear DNA

\begin{tabular}{|c|c|c|c|}
\hline Target lineage & Primers & Sequences $\left(5^{\prime}-3^{\prime}\right)$ & Size (bp) \\
\hline \multirow[t]{2}{*}{ Plasmodium } & L9 & 5'-AAACAATTCCTAACAAAACAGC-3' & \multirow[t]{2}{*}{188} \\
\hline & NewR & 5'-ACATCCAATCCATAATAAAGCA-3' & \\
\hline \multirow[t]{2}{*}{ Haemoproteus } & HmajF2 & 5'-GCAGAACAAAGAAATTTAACATCA-3' & \multirow[t]{2}{*}{83} \\
\hline & HmajR2 & 5'-AAACCAAATTGTAGGTACGGAGTA-3' & \\
\hline \multirow[t]{2}{*}{ Host primers } & $\mathrm{SFSR} / 3 \mathrm{Fb}$ & 5'-ACTAGCCCTTTCAGCGTCATGT-3' & \multirow[t]{2}{*}{114} \\
\hline & $\mathrm{SFSR} / 3 \mathrm{Rb}$ & 5'-CATGCTCGGGAACCAAAGG-3' & \\
\hline
\end{tabular}

10 individuals with mixed infections. Firstly, PCR products were purified (MinElute PCR Purification Kit; Qiagen), then cloned using StrataClone ${ }^{\mathrm{TM}}$ PCR Cloning Kit (Stratagen). From each individual, we sequenced 3-12 clones to identify the parasite lineages present in the mix. In a sample of 10 tested individuals, the set of lineages identified by cloning and by visual comparison of lineages were in complete accordance.

To assess the intensity of infection, genomic DNA from the subset of positive samples was re-extracted from blood using a standard ammonium acetate method and total DNA concentration was measured using a NanoDrop spectophotometer. All samples were diluted to a standard working concentration of $2 \mathrm{ng} / \mu \mathrm{l}$ prior to qPCR. Standard curves were created using a full-length cyt $b$ PCR product from $P$. circumflexum (lineage pTURDUS1) and from $H$. majoris (hPARUS1), respectively. The standard curves were prepared exactly as described in Knowles et al. (2010). qPCRs were performed on FAST700 real-time PCR instrument (Applied Biosystems). Each reaction of $25 \mu \mathrm{l}$ included $5 \mu \mathrm{l}$ DNA $(2 \mathrm{ng} / \mu \mathrm{l}), 12.5 \mu \mathrm{l}$ SuperMix (Power SYBR Master Mix; Applied Biosystems), $0.5 \mu \mathrm{M}$ of each primer (Table 1) and $\mathrm{ddH}_{2} \mathrm{O}$. Thermal cycling conditions started with an initial incubation at $50{ }^{\circ} \mathrm{C}$ for $2 \mathrm{~min}$ and $95^{\circ} \mathrm{C}$ for $10 \mathrm{~min}$, followed by 42 cycles at $95^{\circ} \mathrm{C}$ for $15 \mathrm{~s}$, and at $60{ }^{\circ} \mathrm{C}$ for $60 \mathrm{~s}$. Each DNA sample was run in duplicate and scored as average values. To get accurate measurements of host DNA in qPCR, a second reaction was carried out with specific primers that amplify a single copy nuclear sequence of a host DNA region (Table 1), which is ultra-conserved across vertebrates as describe in Asghar et al. (2011).

In total, 762 samples from 651 individual Blue Tits were screened for infection with avian malaria parasites. A generalised linear mixed model (Proc GLIMMIX) assuming binomial error distribution and a logit link was performed to study variation in infection status. Year effect along with individual age and sex were defined as fixed categorical variables. The model included higher level random factors: nest ID to account for the fact that males and females shared the same territory/same brood, and individual ID (ring number) to account for multiple samples from the same individual in different years. A total of 91 individuals were screened more than once with the sampling frequency ranging from 2 to 4 seasons. Models were optimised by backward stepwise elimination of non-significant interactions, starting from interactions of the highest order. Three separate models were run. One with all lineages and multiple infections considered together (infected or not infected regardless of the parasite genus), and two separate models with the most numerous avian malaria lineages (pTURDUS1 and hPARUS1). Unfortunately, it was not possible to introduce the genus effect in the model including all parasite species as the genus is known only for infected individuals. Since some birds were involved in the brood size manipulation experiment, we also run the analysis accounting for the effect of experiment (experimentally enlarged broods vs. unmanipulated broods). However, this factor and interactions involving this effect appeared nonsignificant. In fact, we do not have clear expectations concerning this effect (there is not enough time from manipulation until blood sampling to develop a new parasitic infection that could be detectable in the blood samples), so we decided to omit the effect of experimental treatment from the final model. More importantly, the removal of experimental treatment does not change the results.

The analyses of intensity of infection were based on the subset of 170 birds sampled in years 2009-2012. In this group, only two individuals were sampled more than once and only data from the first occurrence was used. Data on infection intensity was log-transformed to meet the assumption of normal distribution. We performed general linear mixed model (Proc MIXED) to study variation in the intensity of infection. The model included year of the study, individual age, sex, experimental treatment (experimentally enlarged broods vs. unmanipulated broods) and genus of parasites defined as categorical fixed variables. The model included nest ID as a random factor nested in the experiment to account for the fact that males and females shared the same territory/same brood. The full model was always tested, but then reduced by removing non-significant interactions. All analyses were conducted in SAS 9.3.

\section{Results}

The overall prevalence of infection with malaria parasites (i.e. Plasmodium and Haemoproteus) among 762 screened 
Table 2 Diversity of avian malaria lineages in the Blue Tit (Cyanistes caeruleus) population from Gotland (Sweden) in years 2008-2012 $(n=762)$

\begin{tabular}{lllrr}
\hline Parasite taxon & Lineage & GenBank accession no. & $n$ occurring & Prevalence $(\%)$ \\
\hline Plasmodium circumflexum & TURDUS1 & AF495576 & 275 & 36.1 \\
Plasmodium circumflexum & BT7 & AY393793 & 60 & 7.9 \\
Plasmodium relictum & SGS1 & AF495571 & 16 & 2.1 \\
Plasmodium relictum & GRW11 & AY831748 & 2 & 0.3 \\
Plasmodium polare & SW2 & AF495572 & 377 & 0.3 \\
Pooled Plasmodium & & & 117 & 49.5 \\
Haemoproteus majoris & PARUS1 & AF254977 & 2 & 15.4 \\
Haemoproteus majoris & PHSIB1 & AF495565 & 1 & 0.3 \\
Haemoproteus majoris & WW2 & AY831755 & 126 & 0.1 \\
Pooled Haemoproteus & & & 497 & 65.2 \\
Plasmodium + Haemoproteus & & &
\end{tabular}

Based on sequence data from a 478-bp fragment of the mitochondrial cytochrome $b$ gene, 8 lineages of avian malaria were detected. The prevalence is presented as the percent of individuals harbouring single infections with a given malaria lineage. The prevalence of pooled lineages of Plasmodium and Haemoproteus include cases of mixed infections, which were present at a low rate $(2.8 \%)$

Table 3 Repeatability of malaria infection status in adult Blue Tits captured in multiple (usually successive) breeding seasons $(2008-2012 ; n=91)$

Cases with the same lineage of avian malaria between seasons are in parentheses

\begin{tabular}{|c|c|c|c|c|c|}
\hline \multirow[t]{3}{*}{ First year } & \multicolumn{5}{|c|}{ Successive year } \\
\hline & \multirow[t]{2}{*}{ Not infected } & \multicolumn{4}{|c|}{ Infected } \\
\hline & & Total & Plasmodium & Haemoproteus & Double infections \\
\hline Not infected $(n=31)$ & 9 & 22 & 17 & 5 & - \\
\hline Infected $(n=60)$ & 11 & 49 & 30 & 17 & 2 \\
\hline Infected (Plasmodium) & 8 & - & $28(23)$ & 4 & 2 \\
\hline Infected (Haemoproteus) & 3 & - & 1 & $13(13)$ & - \\
\hline Double infection & - & - & 1 & - & - \\
\hline
\end{tabular}

samples was $65.2 \%$ and varied from 38.1 to $76.2 \%$ among years. The parasites from genus Plasmodium were the most frequently detected (75.9\% of all infections). Altogether, the parasite assemblage was composed of eight different cytochrome $b$ lineages (Table 2): five belonging to three species of genus Plasmodium (P. circumfexum: pTURDUS1, pBT7; $P$. relictum: pSGS1, pGRW11, $P$. polare: pSW2) and three lineages belonging to one species of Haemoproteus ( $H$. majoris: hPARUS1, hPHSIB1, hWW2). The most common lineages, with the prevalence over $2 \%$, were pTURDUS1, hPARUS1, pBT7 and pSGS1 (Table 2). Other lineages were found at frequencies lower than $0.5 \%$. There were 21 birds $(2.8 \%)$ that carried concomitant infections, i.e. simultaneous infections of two parasite lineages (16 cases of double Plasmodium and 5 of Plasmodium and Haemoproteus).

Among 91 individuals sampled more than once, the probability of contracting new infection between successive breeding seasons was higher than the probability of losing an infection or staying uninfected (Table 3). The probability of transition from non-infected to infected was high (0.71), while the probability of opposite transition was low (0.18; Table 3). A new infection with Plasmodium was more likely (17/22) than infection with Haemoproteus (5/22). Among birds being infected in successive years, the probability of changing haplotype was 0.27 (13/49).

The overall prevalence was significantly determined by year $\times$ age interaction: the prevalence was significantly higher among older birds than among yearlings in 3 out of 5 study years (Table 4a; Fig. 1). Separate analyses within the two most common parasite lineages showed also significant effect of year $\times$ age interaction on hPARUS1 prevalence, while pTURDUS1 prevalence was affected by independent effects of year and age (Table $4 b, c)$. We did not find any effect of sex on infection status neither when considering pooled infections nor infections with separate lineages.

The intensity of infection was significantly affected by an interaction between year and genus effects (Table 5; Fig. 2). Separate analysis performed within genus revealed strong effect of the study year on the intensity of infection 
Table 4 Variation in infections status: (a) all malaria parasites pooled together $(n=735)$, (b) infections with pTURDUS1 $(n=518)$ and (c) hPARUS1 $(n=370)$

\begin{tabular}{llllr}
\hline Predictors & DF & Den DF & $F$ value & $\operatorname{Pr}>F$ \\
\hline (a) Pooled malaria & & & & \\
Year & 4 & 481.8 & 6.16 & $<\mathbf{0 . 0 0 0 1}$ \\
Sex & 1 & 724 & 0.43 & 0.5137 \\
Age & 1 & 724 & 4.91 & $\mathbf{0 . 0 2 7 1}$ \\
Year $\times$ age & 4 & 724 & 2.61 & $\mathbf{0 . 0 3 4 4}$ \\
(b) pTURDUS1 & & & & \\
Year & 4 & 396.5 & 8.70 & $<\mathbf{0 . 0 0 0 1}$ \\
Sex & 1 & 511 & 0.00 & 0.9587 \\
Age & 1 & 511 & 4.36 & $\mathbf{0 . 0 3 7 3}$ \\
(c) hPARUS1 & & & & \\
Year & 4 & 359 & 1.56 & 0.1832 \\
Sex & 1 & 347 & 2.93 & 0.0878 \\
Age & 1 & 359 & 9.96 & $\mathbf{0 . 0 0 1 7}$ \\
Year $\times$ age & 4 & 359 & 3.11 & $\mathbf{0 . 0 1 5 4}$ \\
\hline
\end{tabular}

Presented are the results of the generalized linear mixed model (Proc GLIMMIX in SAS) using binomial errors and a logit link. The model included nest ID and individuals ID as random higher order factoreffect not shown. All interactions were considered but discarded from the final model if non-significant

Significant terms $(p<0.05)$ are shown in bold

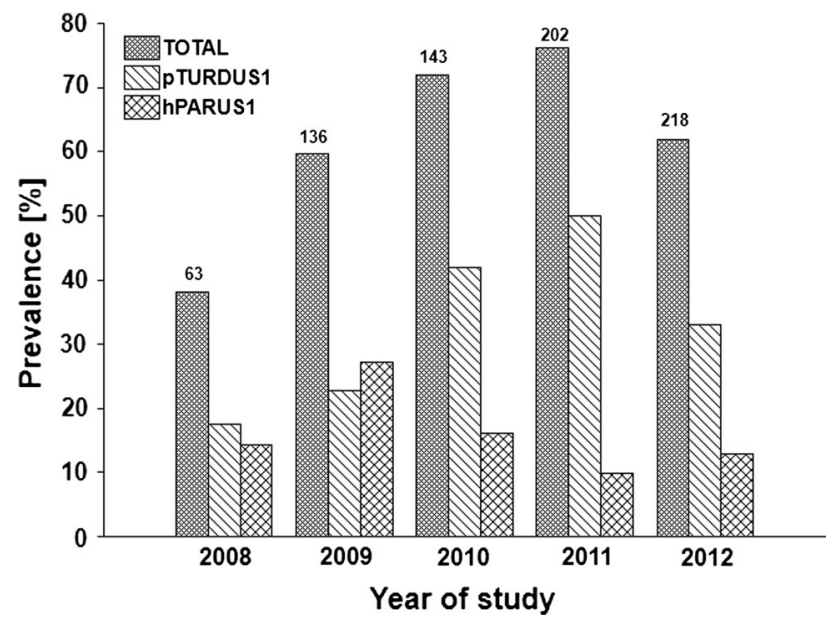

Fig. 1 Annual variation in prevalence of avian malaria in Blue Tits (Cyanistes caeruleus) from Gotland in years 2008-2012. The total prevalence (pooled malaria infections) and the prevalence of the two most common lineages pTURDUS1 and hPARUS1 are shown. Numbers above bars indicate the number of birds screened for parasites

with pTURDUS1 $\left(F_{3,60.7}=4.89, p=0.0042\right)$, but such effect was not apparent for hPARUS1 $\left(F_{3,33.8}=1.24\right.$, $p=0.3108)$. The infection intensity was significantly lower for pTURDUS1 than for hPARUS1 in 3 out of 4 study years (Fig. 2). We failed to show any significant effect of age, sex and experimental treatment on the intensity of infection (Table 5).
Table 5 Variation in infection intensity for (a) pooled avian malaria parasites $(n=162)$ and separately for the most common lineages: (b) pTURDUS1 $(n=85)$ and (c) hPARUS1 $(n=45)$

\begin{tabular}{lllll}
\hline Predictors & DF & Den DF & $F$ value & $\operatorname{Pr}>F$ \\
\hline
\end{tabular}

(a) Pooled malaria

$\begin{array}{lllrr}\text { Year } & 3 & 114 & 1.67 & 0.1778 \\ \text { Sex } & 1 & 98.8 & 0.01 & 0.9054 \\ \text { Age } & 1 & 146 & 0.29 & 0.5888 \\ \text { Experiment } & 1 & 95.7 & 1.24 & 0.2688 \\ \text { Genus } & 1 & 151 & 115.25 & <\mathbf{0 . 0 0 0 1} \\ \text { Year } \times \text { genus } & 3 & 150 & 6.01 & \mathbf{0 . 0 0 0 7}\end{array}$

(b) pTURDUS1

$\begin{array}{lllll}\text { Year } & 3 & 60.7 & 4.89 & \mathbf{0 . 0 0 4 2} \\ \text { Sex } & 1 & 55.4 & 0.20 & 0.6543 \\ \text { Age } & 1 & 76.8 & 2.37 & 0.1276 \\ \text { Experiment } & 1 & 60.7 & 1.22 & 0.2745 \\ \text { (c) hPARUS1 } & & & & \\ \text { Year } & 3 & 33.8 & 1.24 & 0.3108 \\ \text { Sex } & 1 & 28.4 & 0.16 & 0.6880 \\ \text { Age } & 1 & 35.9 & 0.04 & 0.8455 \\ \text { Experiment } & 1 & 33.4 & 0.05 & 0.8294\end{array}$

Presented are the results of the general linear model (Proc MIXED in SAS). The model included nest ID as random higher order factor nested in experiment-effect not shown

Significant terms $(p<0.05)$ are shown in bold

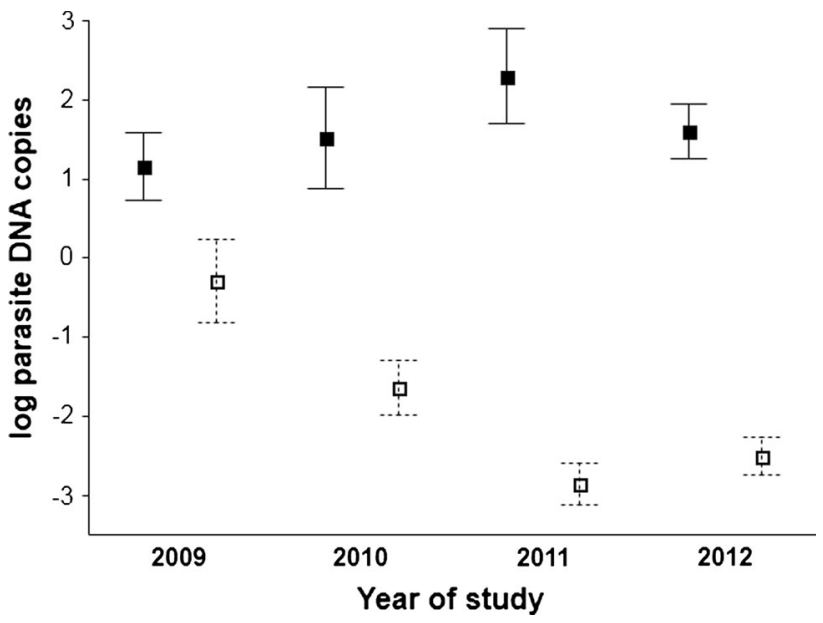

Fig. 2 Annual variation in intensity of infection with a Plasmodium (open squares, dashed line) and $\mathbf{b}$ Haemoproteus (filled squares, solid line). Points present least square means and standard errors. The differences in intensity of infection among above genera were significant in 3 out of 4 study years (Tukey HSD, 2009: $p=0.383$; 2010: $p=0.0004$; 2011: $p<0.0001 ; 2012: p<0.0001)$

\section{Discussion}

The assemblage of avian malaria parasites presented in our study differed from the ones described previously for the same population by Szöllősi et al. (2011) and Merilä and 
Andersson (1999). In the set of samples collected in 2005, Szöllösi et al. (2011) reported the general prevalence of $87.9 \%$ with the majority of infections caused by Plasmodium (75\%). In contrast to our study, the authors detected much lower lineage diversity (only three lineages: pTURDUS1, hPARUS1, pBT7). In the set of samples collected in 1994, Merilä and Andersson (1999) reported a much lower general prevalence of parasites (27\% in 259 individuals) than in Szöllösi et al. (2011) and in the current study, and domination of parasites from genus Haemoproteus (84\% of infections). The discrepancy between the current and previous studies may be associated with the pattern of sampling (several breeding seasons vs. a single breeding season) and differences in the sample size $\left(n_{\mathrm{M} \& \mathrm{~A}}=259\right.$; $n_{\mathrm{Sz}}=41 ; n_{\text {here }}=762$ ). Moreover, in the study of Merilä and Andersson (1999), detection of blood parasites was based on screening of blood smears. This traditional method is known to underestimate the prevalence as one may miss the occurrence of infections at low intensities (Jarvi et al. 2002; Fallon et al. 2003; Waldenström et al. 2004). In fact, the intensity of infection with Plasmodium is usually far lower than caused by Haemoproteus (Valkiūnas 2005), the pattern also found in our study. Thus, it is likely that, because of low sensitivity of the method applied by Merilä and Andersson (1999), the Plasmodium infections showed lower detectability and the general prevalence was underestimated.

We reported several lineages which were previously not detected in this population. Most of them were observed in less than a handful of individuals (pSGS1, pGRW11, pSW2, hPHSIB1 and pWW2: 3.2, 0.4, 0.4, 0.4 and $0.2 \%$ of all infections, respectively). Such low prevalence may make detection of rare lineages very difficult when the sample size is small. It is possible that these lineages mainly depend on other hosts and that the observed infections are sporadic 'spillovers' from such main hosts (Woolhouse et al. 2001). Indeed, four of the rare lineages observed in the study population of Blue Tits have been also encountered in sympatrically occurring host speciesthe Great Tit (Parus major) and the Collared Flycatcher (Ficedula albicollis) (own unpublished data).

Our study shows that the malaria infection status and intensity vary across years. The annual variation in infection status and intensity with malaria parasite has been repeatedly reported (e.g. Schall and Marghoob 1995; Bensch et al. 2007; Wood et al. 2007; Lachish et al. 2011b). Clear cyclicity in malaria prevalence has been observed in lizards (Schall and Marghoob 1995) and birds (Bensch et al. 2007), with a periodicity of about 10 years in lizards and 3-4 years in birds. This may result from fluctuations in environmentally driven variation in vector abundance, parasite-mediated population cycles (Hudson et al. 1998) or patterns of selection with respect to parasite resistance (Little and Ebert 2001; Westerdahl et al. 2004). We observe clear yearly differences in infection prevalence and intensity, but the time series in our study is too short to draw any conclusions on any regular fluctuations.

Individual age appeared to be a significant determinant of infection status, with higher prevalence in older birds. This may be explained by the relatively high probability of contracting an infection in successive year. We found $71 \%$ of uninfected individuals to become infected in successive years, whereas the infection disappeared in only $18 \%$ of infected individuals. Similarly, a number of previous studies also reported an increase in prevalence with age (e.g. Weatherhead and Bennett 1991; Norris et al. 1994; Seutin 1994; Deviche et al. 2001). We did not find any effect of sex on infection status, when considering either pooled infections or infections with separate lineages (pTURDUS1, hPARUS1). We failed to find any impact of brood size manipulation on parasitaemia, even though previous studies have shown elevated reproductive effort to increase the intensity of infection (e.g. Knowles et al. 2009).

Acknowledgments We would like to thank Giulia Casasole, Joanna Sudyka and Dariusz Wiejaczka for assistance with the fieldwork. Financial support was provided by the National Science Centre, Grant nr 2011/03/N/NZ8/02106 to E.P. and N N304 336039 to A.D. The long term nest box study was supported by the Swedish Research Council (grant to L.G.). The study conforms to the legal requirements of Sweden.

Open Access This article is distributed under the terms of the Creative Commons Attribution License which permits any use, distribution, and reproduction in any medium, provided the original author(s) and the source are credited.

\section{References}

Asghar M, Hasselquist D, Bensch S (2011) Are chronic avian haemosporidian infections costly in wild birds? J Avian Biol 42:530-537

Bensch S, Waldenström J, Jonzén N, Westerdahl H, Hansson B, Sejberg D, Hasselquist D (2007) Temporal dynamics and diversity of avian malaria parasites in a single host species. J Anim Ecol 76:112-122

Cosgrove CL, Wood MJ, Day KP, Sheldon BC (2008) Seasonal variation in Plasmodium prevalence in a population of blue tits Cyanistes caeruleus. J Anim Ecol 77:540-548

Deviche P, Greiner EC, Manteca A (2001) Seasonal and age-related changes in blood parasite prevalence in dark-eyed Juncos (Junco hyemalis, Aves, Passeriformes) J Exp Zoo 289:456-466

Fallon SM, Ricklefs RE, Swanson BL, Bermingham E (2003) Detecting avian malaria: an improved polymerase chain reaction diagnostic. J Parasitol 89:1044-1047

Hudson PJ, Dobson AP, Newborn D (1998) Prevention of population cycles by parasite removal. Science 282:2256-2258

Jarvi SI, Schultz JJ, Atkinson CT (2002) PCR diagnostics underestimate the prevalence of avian malaria (Plasmodium relictum) in experimentally-infected passerines. J Parasitol 88:153-158 
Knowles SCL, Nakagawa S, Sheldon BC (2009) Elevated reproductive effort increases blood parasitaemia and decreases immune function in birds: a meta-regression approach. Funct Ecol 23:405-415

Knowles SCL, Palinauskas V, Sheldon BC (2010) Chronic malaria infections increase family inequalities and reduce parental fitness: experimental evidence from a wild bird population. J Evol Biol 23:557-569

Lachish S, Knowles SCL, Alves R, Wood MJ, Sheldon BC (2011a) Fitness effects of endemic malaria infections in a wild bird population: the importance of ecological structure. J Anim Ecol 80:1196-1206

Lachish S, Knowles SCL, Alves R et al (2011b) Infection dynamics of endemic malaria in a wild bird population: parasite speciesdependent drivers of spatial and temporal variation in transmission rates. J Anim Ecol 80:1207-1216

Little TJ, Ebert D (2001) Temporal patterns of genetic variation for resistance and infectivity in a Daphnia-microparasite system. Evolution 55:1146-1152

Merilä J, Andersson M (1999) Reproductive effort and success are related to haematozoan infections in blue tits. Ecoscience 6:421-428

Norris K, Anwar M, Read AF (1994) Reproductive effort influences the prevalence of haematozoan parasites in great tits. J Anim Ecol 63:601-610

Palinauskas V, Valkiūnas G, Bolshakov CV, Bensch S (2008) Plasmodium relictum (lineage P-SGS1): effects on experimentally infected passerine birds. Exp Parasitol 120:372-380

Palinauskas V, Valkiūnas G, Bolshakov CV, Bensch S (2011) Plasmodium relictum (lineage SGS1) and Plasmodium ashfordi (lineage GRW2): the effects of the co-infection on experimentally infected passerine birds. Exp Parasitol 127:527-533

Pérez-Tris J, Hasselquist D, Hellgren O, Krizanauskiene A, Waldenström J, Bensch S (2005) What are malaria parasites? Trends Parasitol 21:209-211

Podmokła E, Dubiec A, Drobniak SM, Arct A, Gustafsson L, Cichoń M (2014) Avian malaria is associated with increased reproductive investment in the blue tit. J Avian Biol. doi:10.1111/j.1600048X.2013.00284.x (in press)

Poulin R (1996) Helminth growth in vertebrate hosts: does host sex matter? Int J Parasitol 26:1311-1315

Przybylo R, Sheldon BC, Merilä J (2000) Climatic effects on breeding and morphology: evidence for phenotypic plasticity. J Anim Ecol 69:395-403
Ricklefs RE, Fallon SM, Bermingham E (2004) Evolutionary relationships, cospeciation, and host switching in avian malaria parasites. Syst Biol 53:111-119

Schalk G, Forbes MR (1997) Male biases in parasitism of mammals: effects of study type, host age, and parasite taxon. Oikos 78:67-74

Schall JJ, Marghoob AB (1995) Prevalence of a malarial parasite over time and space: Plasmodium mexicanum in its vertebrate host, the western fence lizard Sceloporus occidentalis. J Anim Ecol 64:177-185

Schuurs AH, Verheul HA (1990) Effects of gender and sex steroids on the immune response. J Steroid Biochem 35:157-172

Seutin G (1994) Plumage rednesss in redpoll finches does not reflect hemoparasitic infection. Oikos 70:280-286

Svensson L (1994) Identification guide to European passerines. Svensson, Stockhom

Szöllősi E, Cichoń M, Eens M, Hasselquist D, Kempenaers B, Merino S, Nilsson J-Å, Rosivall B, Rytkönen S, Török J, Wood MJ, Garamszegi LZ (2011) Determinants of distribution and prevalence of avian malaria in blue tit populations across Europe: separating host and parasite effects. J Evol Biol 24:2014-2024

Valkiūnas G (2005) Avian malaria parasites and other haemosporidia. CRC, Boca Raton

Waldenström J, Bensch S, Hasselquist D, Östman Ö (2004) A new nested PCR method very efficient in detecting Plasmodium and Haemoproteus infections from avian blood. $\mathrm{J}$ Parasitol 90:191-194

Walsh PS, Metzger DA, Higuchi R (1991) Chelex ${ }^{\circledR} 100$ as a medium for simple extraction of DNA for PCR-based typing from forensic material. Biotechniques 10:506-513

Weatherhead PJ, Bennett GF (1991) Ecology of Red-winged Blackbird parasitism by haematozoa. Can J Zool 69:2352-2359

Westerdahl H, Hansson B, Bensch S, Hasselquist D (2004) Between year variation of $\mathrm{MHC}$ allele frequencies in great reed warblers: selection or drift? J Evol Biol 17:485-492

Wilson K, Bjørnstad ON, Dobson AP et al (2001) Heterogeneities in macroparasite infections: patterns and processes. In: Hudson PJ, Rizzoli A, Grenfell BT, Heesterbeek H, Dobson AP (eds) The ecology of wildlife diseases. Oxford University Press, Oxford

Wood MJ, Cosgrove CL, Wilkin TA, Knowles SCL, Day KP, Sheldon BC (2007) Within-population variation in prevalence and lineage distribution of avian malaria in blue tits, Cyanistes caeruleus. Mol Ecol 16:3263-3273

Woolhouse MEJ, Taylor LHT, Haydon DT (2001) Population biology of multihost pathogens. Science 292:1109-1112 